\title{
Extracorporeal shock wave therapy in the treatment of tennis elbow: the ASSERT database
}

\author{
Gayle Maffulli ${ }^{1}$ \\ Enzo luliano ${ }^{2}$ \\ Johnny Padulo 2,3 \\ Jan Rompe ${ }^{4}$ \\ Ludger Gerdesmeyer ${ }^{5}$ \\ Nicola Maffulli6,7 \\ 1 Wholelife Clinics, London, UK \\ 2 University eCampus, Novedrate, Italy \\ ${ }^{3}$ Faculty of Kinesiology, University of Split, Split, \\ Croatia \\ ${ }^{4}$ OrthoTrauma Evaluation Institute, Mainz, Germany \\ 5 Department of Orthopaedic Surgery and Traumatolo- \\ gy, University Schlswig, Holstein, Campuskiel, Keil, \\ Germany \\ ${ }^{6}$ Department of Musculoskeletal Disorders, Faculty of \\ Medicine and Surgery, University of Salerno, \\ Salerno, Italy \\ 7 Centre for Sports and Exercise Medicine, Barts and \\ the London School of Medicine and Dentistry, Mile \\ End Hospital, London, UK
}

Corresponding author:

Nicola Maffulli

Department of Musculoskeletal Disorders

School of Medicine and Surgery

University of Salerno,

Mary University of London

Barts and the London School of Medicine and Dentistry

Centre for Sports and Exercise Medicine

Mile End Hospital 275 Bancroft Road

E1 4DG, London, England, UK

Tel.: +447989358279

E-mail:n.maffulli@qmul.ac.uk

\section{Summary}

Introduction: This study aimed to determinate the effectiveness of ESWT in the management of tennis elbow (TE) in both the short and long term.

Methods: Participants were recruited by different clinicians of the National Health Service (NHS) and private sector centres in the United Kingdom. Data were collected in a web-based database [Assessment of the Effectiveness of Extracorporeal Shock Wave Therapy (ESWT) for soft tissue Injuries (ASSERT)]. The 59 participants (mean age $52.51 \pm 10.33$ y) underwent a standardized ESWT protocol. At baseline, 3, 6, 12 and 24 months following ESWT treatment, participants were evaluated with the Visual Analogue Scale (VAS) for pain perception, the Patient-rated Tennis Elbow Evaluation scale (PRTEE) for functional limitation assessment, and the 6 scores of EuroQol-5D questionnaire (EQ-5D) for quality of life.

Results: There was a significant improvement over time in $\mathbf{5}$ of the $\mathbf{8}$ analysed scores (all with at least $(p=0.001)$. In particular, the scores which significantly improved were VAS, PRTEE, and 3 scores of EQ-5D (Pain/Discomfort, Usual Activities and Thermometer Scale).

Conclusion: ESWT showed beneficial effects on TE over a 24-month follow-up period.

Level of evidence: IV.

KEY WORDS: extracorporeal shock wave therapy, lateral epicondylitis, longitudinal study, tennis elbow.

\section{Introduction}

Tennis elbow (TE) is the common name used for lateral epicondylitis. This condition is associated with pain or inflammation on the lateral of the elbow, at and around the lateral epicondyle. Other symptoms may include stiffness or weakness in the elbow and arm. Tennis elbow is usually caused by injury or overuse. Customary treatments offered for this condition include: rest, ice, anti-inflammatory and pain-relieving medication, physiotherapy, physical exercises, orthotic supports and controversially, corticosteroid injection. Shockwave therapy for TE was one of the first most successful treatments used in the orthopaedic arena. Several investigations studied the effect of shockwave therapy in patients with tennis elbow, with a success rate ranging from $68 \%$ to $91 \%{ }^{1-7}$. Extracorporeal shock wave therapy (ESWT) is widely used in the management of TE, with conflicting reports on the effectiveness of the treatment. A metaanalysis identified that ESWT had little or no effect on lateral epicondylitis ${ }^{8}$. However, the meta-analysis did not consider the heterogeneity of the studies included, and also reviewed both acute and chronic cases despite evidence demonstrating that chronic cases benefit more from shockwave therapy ${ }^{9}$. Different shock wave devices and ESWT associated with local anaesthesia were also included in the meta-analysis, despite evidence that the use of local anaesthesia re- 
duces the effectiveness of the treatment ${ }^{10,11}$.

Researchers in the field have called for additional investigations, using homogenous interventions, identical outcome assessment, comparable participants, and comparable follow-up evaluations ${ }^{12}$. Such studies can be performed using large database analyses $^{13}$. The National Institute for Health and Clinical Excellence (NICE) recommends that the results of ESWT are monitored, and clinicians undertaking such procedure make special arrangements for audit ${ }^{14}$. The Assessment of Effectiveness of ESWT for soft tissue injuries (ASSERT) is one such database, the aim of which is to determine the effectiveness of ESWT in patients suffering from selected soft tissue injuries in both the short and long term ${ }^{15}$.

This study evaluated the effectiveness of ESWT in patients with chronic TE enrolled in ASSERT over 24 months considering different aspects, namely the reduction of the clinical severity of symptoms, the relief of pain, and the improvement of the quality of life. Furthermore, this study also aimed to analyse the effects that certain variables such as age, gender, menopausal status, and prior symptoms may have on outcome.

\section{Materials and methods}

The ASSERT database was used to collect information on the effectiveness of ESWT across the United Kingdom. The ESWT machines were standardised and a standardised treatment protocol, together with standardised baseline measurements and outcome measures and time points in centres across the United Kingdom, were adopted to aid validity ${ }^{15}$.

\section{Recruitment}

Participants were recruited from both the National Health Service (NHS) and private sector centres in the United Kingdom. Clinicians recruited participants presenting with insertional plantar fasciitis, and for whom ESWT was indicated as the treatment choice.

\section{Participants}

Participants were included if they were over the age of 18 , had a diagnosis of TE confirmed by the recruiting clinician; undergone a course of conservative therapy which had not been effective in relieving symptoms; been recommended to receive ESWT at one of the recruiting centres; not been diagnosed with inflammatory arthropathy; and demonstrated the ability to give informed consent.

A total of 59 participants (25 males and 34 females) were enrolled and all met the inclusion criteria and were considered for analysis (Tab. I).

This study has been designed and conducted in accordance with the principles of the Declaration of Helsinki and it has been approved by the Local Ethics Committee (11/LO/0253). A written informed consent was obtained from each participant ${ }^{16}$.

\section{Use of ESWT machine}

Standardisation of the machine and the process of administration of ESWT had been agreed to ensure consistency, reproducibility and generalisability of the results. All clinicians using the Swiss DolorClast device (Electro Medical Systems SA, Nyon, Switzerland) and Stortz devices (Stortz Medical AG, Tägerwilen, Switzerland) received training and certification to ensure adherence to the protocol. All clinicians followed a standardised method of administration of ESWT. ${ }^{17}$ This included delivering an initial 500 "warm-up" impulses at a low air pressure (1.5 bar of air pressure). This reduces the pain which patients experience during treatment. Based on patient feedback, the clinician then increased the air pressure to 2.5 bar or above. The total dose of impulses remained constant at 2500 per session, with one session a week for three planned consecutive weeks, with a maximum gap between two consecutive treatments of two weeks.

\section{Database}

The ASSERT database is a web-based system (www.assert.org.uk) from which the clinician received a study number for each participant ${ }^{15}$. Only unidentifiable information with the patients' study number was entered into the database. Sensitive data are held on secure servers. Following informed consent, the clinician recorded the following information: (1) Diagnosis: this was formulated on clinical grounds and some clinicians also used imaging to confirm the diagnosis; (2) Area treated/condition presented with; (3) Date of presentation of symptoms; (4) Date of treatment of

\section{Table I. Sample of participants.}

\begin{tabular}{llll}
\hline & $\mathbf{n}$ & Age $(\mathbf{y})$ & $\begin{array}{l}\text { Number of previous } \\
\text { treatments }\end{array}$ \\
\hline Participants enrolled and considered for analyses & 59 & $52.51 \pm 10.33$ & $1.77 \pm 1.33$ \\
Male & 25 & $50.17 \pm 10.21$ & $1.50 \pm 1.10$ \\
Female & 34 & $54.21 \pm 10.23$ & $1.97 \pm 1.47$ \\
With menopause & 18 & $61.78 \pm 6.61$ & $1.76 \pm 1.03$ \\
Without menopause & 16 & $45.13 \pm 4.94$ & $2.20 \pm 1.86$ \\
\hline
\end{tabular}


ESWT; (5) Code for clinicians centre; (6) Centre where treatment was administered; (7) Previous treatments prior to consultation; (8) Side treated; (9) Dates when ESWT was administered; (10) Baseline scores recorded: EuroQol questionnaire scores (EQ5D) ${ }^{18}$, Visual Analogue Scale for pain (VAS) ${ }^{19}$, and Patient-rated Tennis Elbow Evaluation scale (PRTEE) ${ }^{20}$; (11) Follow-up scores at 3, 6, 12 and 24 months post treatment; (12) Satisfaction: rated poor, satisfactory, good or excellent; (13) Time to effective treatment; (14) Recurrence of the condition; (15) Complications; and (16) Adverse events.

\section{Baseline and follow-up assessments}

After having obtained written informed consent, the treating clinician undertook baseline assessments. The follow-up assessments were instead performed after 3, 6, 12 and 24 months' post treatment. The coordinators of ASSERT undertook all follow-up assessments via email, telephone or post.

\section{Outcome assessment}

The EQ-5D ${ }^{18}$, VAS for pain ${ }^{19}$ and PRTEE 20 were completed by the participants.

The EQ-5D is a standardised measure of health status developed by the EuroQol Group to provide a simple, generic measure of health for clinical and economic appraisal. For the present study, the version $3 L$ (EQ-5D-3L) was used. This is a simple questionnaire composed of 5 items with a 3-point scale answer for each item and designed for completion by the person being treated. Each one of the 5 items respectively investigates 5 dimensions of the quality of life, namely (1) mobility, (2) self-care, (3) usual activities, (4) pain/discomfort, and (5) anxiety/depression. A score from 1 (best score) to 3 (worst score) is assigned for each dimension. The EQ-5D also includes a scale, named EQ-5D Thermometer Scale, that allows obtaining a global score to generally describe the quality of life of the patient. It consists in a vertical line, $100 \mathrm{~mm}$ in length, anchored by 2-word descriptors at each end, which are "the worst health you can imagine" and "the best health you can imagine". Patients are asked to mark on the line the point which they feel represents their perception of their current health status. The score ranges from 0 (worst health status) to 100 (best health status), and it is computed by measuring the distance (in $\mathrm{mm}$ ) between the end of the line marked with "the worst health you can imagine" and the mark on the line indicated by the patient.

The VAS for pain is very similar to the EQ-5D Thermometer Scale, but it focuses only on the pain perceived by the patient, not on the overall quality of life. It consists in a horizontal line, $100 \mathrm{~mm}$ in length, which asks the patients "How severe is your pain today?". The line is anchored by 2-word descriptors at each end, which are "no pain" and "very severe pain". Also, in this case, patients mark on the line the point which they feel represents their current perception of their pain intensity. The score, from 0 (no pain) to 100 (very severe pain), is computed as the measurement of the distance (in $\mathrm{mm}$ ) between the end of the line marked with "no pain" and the point on the line indicated by the patient.

The PRTEE scale is a brief questionnaire assessing the average pain and function of the affected arm during the preceding week. The questionnaire consists of two parts: part 1 deals with pain and part 2 deals with function. The scores obtained by all the items of the 2 parts provide a total score, ranging from 0 (no pain and no functional impairment) to 100 (worst pain imaginable with a very significant functional deficit) 20 .

\section{Statistical analysis}

Linear Mixed Model analysis (LMM) with maximum likelihood method was performed in order to evaluate the significant effects over time produced by ESWT in the treatment of the TB. To perform the LMM analysis, one fixed factors were considered that was Time factor (fixed factor: T0 vs T3 vs T6 vs T12 vs T24) to investigate differences over time. The VAS and the PRTEE scores, as well as the 6 scores of the EQ-5D were considered as dependent variables for the analysis.

The age and the number of previous treatments were considered as covariates of the analysis to verify if these factors could have influenced the VAS, PRTEE and EQ-5D scores over time.

Successively, another LMM analysis was performed on the female participants only to evaluate differences between women with and without menopause. This analysis was performed using 2 fixed factors: Time factor (fixed factor: T0 vs T3 vs T6 vs T12 vs T24), and menopause factor (fixed factor: menopause vs no-menopause). Also, in this case the interaction between the 2 factors were considered (TimexMenopause). The VAS, PRTEE, and the 6 scores of the EQ-5D were considered as dependent variables for the analysis. If two or more of the follow-up datasets were missing the patient was excluded.

Due to the multiple dependent variables, the Bonferroni correction was used adjust the $p$-value. The Bonferroni correction indicate an adjusted $p<0.006$ for significance.

When a significant effect over time was detected, Bonferroni post-hoc analysis (adjusted for multiple comparison) was used to perform comparisons in pair among the different time of assessments.

All the analyses were performed with the statistical software SPSS 20 (IBM Corporation, Chicago, IL, USA).

\section{Results}

The analyses showed a significant reduction over time of the VAS score $\left(F_{4,127}=35.747 ; p<0.0001\right)$, whereas no significant differences were found between the two genders $\left(F_{1,50}=0.061 ; p=0.806\right)$ and in the interaction TimexGender $\left(F_{4,127}=2.878 ; p=0.025, p\right.$-value 
not significant after Bonferroni correction).

Concerning the PRTEE scores, the analysis showed a significant reduction over time $\left(F_{4,118}=18.372\right.$; $p<0.0001)$, with no significant differences between the two genders $\left(F_{1,57}=0.245 ; p=0.623\right)$ and in the interaction TimexGender $\left(F_{4,118}=1.893 ; p=0.116\right)$.

Concerning the EQ-5D questionnaire domains, the analysis showed the following results: the EQ-5D Anxiety/Depression score did not show significant differences both in Time $\left(F_{4,118}=0.967 ; p=0.428\right)$ and Gender $\left(F_{1,58}=1.271 ; p=0.264\right)$, and similarly also in the interaction TimexGender $\left(F_{4,118}=0.728 ; p=0.575\right)$; similarly, no significant modification over time were found in the EQ5D Mobility score $\left(F_{4,99}=0.206 ; p=0.935\right)$, or between the two genders $\left(F_{1,43}=0.163 ; p=0.688\right)$ and in the interaction TimexGender $\left(F_{4,99}=0.299 ; p=0.878\right)$; significant reduction over time was instead found in the EQ-5D

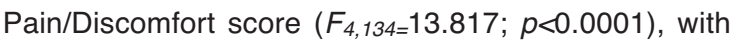
no significant differences between the two genders $\left(F_{1,52}=0.026 ; p=0.873\right)$ and in the interaction TimexGender $\left(F_{4,134}=1.013 ; p=0.403\right)$; the analysis showed once again a significant reduction over time of the EQ-5D Usual Activities score $\left(F_{4,135}=6.205\right.$; $p=0.0001)$, with no significant differences were found between the two genders $\left(F_{1,56}=1.050 ; p=0.310\right)$ and in the interaction TimexGender $\left(F_{4,135}=0.881 ; p=0.477\right)$; conversely, the EQ-5D Self-Care did not show significant differences both in Time $\left(F_{4,115}=3.637 ; p=0.008\right.$, not significant after Bonferroni correction) and Gender $\left(F_{1,48}=2.058 ; p=0.158\right)$, and in the interaction TimexGender $\left(F_{4,115}=0.910 ; p=0.461\right)$; finally, the EQ5D Thermometer Scale analysis showed significant differences in Time $\left(F_{4,119}=5.226 ; p=0.001\right)$ but no differences were found between genders $\left(F_{1,52}=0.037\right.$; $p=0.848)$, and in the interaction Time $\times$ Gender $\left(F_{4,119}=0.813 ; p=0.519\right)$.

The involvement in previous treatment and the age of the patients seem to not have produced significant influences on all the analysed dependent variables (no significant $p$-values for all the variables).

The LMM analysis performed to evaluate whether differences existed in the analysed variables between female patients with and without menopause showed that no differences existed in any analysed variables.

\section{Discussion}

The present study showed ESWT is safe and effective. The results showed significant results in 5 scores of 8 analysed.

The VAS and the PRTEE scores reported a significant amelioration after only 3 months, with no additional improvement during the 24 months of observation.

The same trend was obtained also for the EQ-5D Thermometer Scale and Pain/Discomfort scores. On the contrary, the EQ-5D Usual Activities score reported a significant improvement compared to baseline, after 6 months. Also, in this case, no additional improvement during the 24 months was observed.
ESWT produced significant positive effects in reducing pain and improving the ability of the patients to manage everyday life, as indicated by the significant amelioration of VAS and PRTEE score respectively. Also, the quality of life and the health status was significantly enhanced after ESWT intervention as suggested by the overall improvement of EQ-5D scores. However, the baseline scores of the Mobility, Anxiety/Depression and Self-Care dimensions' scores (Table II) were markedly low, and they remained low for all the duration of the follow-up. Consequently, the non-significant modification of these three scores was probably attributable to a low impact of TE on these dimensions since the baseline assessment, especially with relation to Mobility in patients with TE, does not affect a person's mobility. Another clinically important finding concerns the time necessary to obtain significant benefits on health status and pain relief. In fact, there was a significant improvement three months after the last session of ESWT in VAS, PRTEE, EQ-5D Pain/Discomfort, EQ5D Usual Activities and the EQ-5D Thermometer Scale score in comparison to the baseline score. Given these results, ESWT can be considered a valid and effective method for the treatment of TE. Furthermore, previous treatments, the age, the gender and the presence/absence of menopause do not exert significant influences on the efficacy of ESWT. The influence of these factors was generally not considered in previous studies, and could represent an additional strength for the use of this modality in the management of TE, regardless of gender or age.

The results of the present study are in keeping with a number of well-conducted studies showing positive results $5,21-25$, and confirm that ESWT should be used in patients who have correctly diagnosed TE and have experienced symptoms for three months or more. However, further studies are necessary to demonstrate the best treatment regimens with long term follow-up to better define the efficacy of ESWT in the long term comparing shockwave devices with the same shockwave generator ${ }^{12}$. In this respect, the ASSERT database plays an important role. In fact, ASSERT aimed to collect high quality and relevant data about the effectiveness of ESWT in patients with TE in a pragmatic and systematic manner to improve the quality of outcomes and ensure the quality and cost effectiveness of ESWT. ASSERT can monitor the outcomes achieved by practitioners and identify where these fall below an expected performance to inform best practice and additional training requirements.

Some studies reported no effects of ESWT $26-28$ in the treatment of TE, and some aspects of this modality remain unclear. The present evidence $4,5,7,21,22,25$ however clearly indicates ESWT as an effective therapy for the management of TE. No analysis is perfect, and we acknowledge that many other variables such as the amount of energy employed, high vs low intensity shock wave treatment, radial vs focused shock wave treatment, the methods of localization of the 
Table II. Results relative to the effects over time with the post-hoc analyses outputs.

\begin{tabular}{|c|c|c|c|c|c|c|c|c|}
\hline \multirow[t]{2}{*}{ Tests } & & \multirow{2}{*}{$\begin{array}{l}\text { TO } \\
\text { Means } \pm \\
\text { SD (N) }\end{array}$} & \multirow{2}{*}{$\begin{array}{l}\text { T3 } \\
\text { Means } \pm \\
\text { SD (N) }\end{array}$} & \multirow{2}{*}{$\begin{array}{l}\text { T6 } \\
\text { Means } \pm \\
\text { SD (N) }\end{array}$} & \multirow{2}{*}{$\begin{array}{l}\text { T12 } \\
\text { Means } \pm \\
\text { SD (N) }\end{array}$} & \multirow{2}{*}{$\begin{array}{l}\text { T24 } \\
\text { Means } \pm \\
\text { SD (N) }\end{array}$} & \multirow{2}{*}{$\begin{array}{l}\text { Overall } \\
\text { significance } \\
\text { in time }\end{array}$} & \multirow{2}{*}{$\begin{array}{l}\text { Comparisons in } \\
\text { pair - } \\
\text { significance }\end{array}$} \\
\hline & & & & & & & & \\
\hline \multirow[t]{2}{*}{ VAS } & Scores & $\begin{array}{l}62.57 \pm \\
18.49(51)\end{array}$ & $\begin{array}{l}31.74 \pm \\
27.11(42)\end{array}$ & $\begin{array}{l}20.00 \pm \\
21.69(33)\end{array}$ & $\begin{array}{l}16.76 \pm \\
23.79(29)\end{array}$ & $\begin{array}{l}15.05 \pm \\
25.02(21)\end{array}$ & \multirow[t]{2}{*}{$p<0.0001$} & \multirow[t]{2}{*}{$\begin{array}{l}\text { T0 vs T3, T6, } \\
\text { T12; T24 }\end{array}$} \\
\hline & $\begin{array}{l}\text { Difference } \\
\text { with } \\
\text { baseline } \\
\text { score }\end{array}$ & - & -30.83 & -42.57 & -45.81 & -47.52 & & \\
\hline \multirow[t]{2}{*}{ PRTEE } & Scores & $\begin{array}{l}51.80 \pm \\
16.77(44) \\
\end{array}$ & $\begin{array}{l}28.44 \pm \\
23.69(36) \\
\end{array}$ & $\begin{array}{l}26.28 \pm \\
23.00(32)\end{array}$ & $\begin{array}{l}21.17 \pm \\
23.70(29) \\
\end{array}$ & $\begin{array}{l}13.65 \pm \\
22.09(20) \\
\end{array}$ & \multirow[t]{2}{*}{$p<0.0001$} & \multirow[t]{2}{*}{$\begin{array}{l}\text { T0 vs T3, T6, } \\
\text { T12; T24 }\end{array}$} \\
\hline & $\begin{array}{l}\text { Difference } \\
\text { with } \\
\text { baseline } \\
\text { score }\end{array}$ & - & -23.35 & -25.51 & -30.62 & -38.15 & & \\
\hline \multirow[t]{2}{*}{$\begin{array}{l}\text { EQ-5D } \\
\text { Anxiety/Depression }\end{array}$} & Scores & $\begin{array}{l}1.11 \pm \\
0.31(47)\end{array}$ & $\begin{array}{l}1.15 \pm \\
0.37(39)\end{array}$ & $\begin{array}{l}1.16 \pm \\
0.45(32)\end{array}$ & $\begin{array}{l}1.17 \pm \\
0.38(29)\end{array}$ & $\begin{array}{l}1.10 \pm \\
0.31(20)\end{array}$ & \multirow[t]{2}{*}{$\begin{array}{l}\text { Not } \\
\text { significant }\end{array}$} & \multirow[t]{2}{*}{-} \\
\hline & $\begin{array}{l}\text { Difference } \\
\text { with } \\
\text { baseline } \\
\text { score }\end{array}$ & - & 0.05 & 0.05 & 0.07 & -0.01 & & \\
\hline \multirow[t]{2}{*}{ EQ-5D Mobility } & Scores & $\begin{array}{l}1.09 \pm \\
0.35(47) \\
\end{array}$ & $\begin{array}{l}1.05 \pm \\
0.22(39) \\
\end{array}$ & $\begin{array}{l}1.06 \pm \\
0.25(32) \\
\end{array}$ & $\begin{array}{l}1.03 \pm \\
0.19(29) \\
\end{array}$ & $\begin{array}{l}1.05 \pm \\
0.22(20) \\
\end{array}$ & \multirow[t]{2}{*}{$\begin{array}{l}\text { Not } \\
\text { significant }\end{array}$} & \multirow[t]{2}{*}{-} \\
\hline & $\begin{array}{l}\text { Difference } \\
\text { with } \\
\text { baseline } \\
\text { score }\end{array}$ & - & -0.03 & -0.02 & -0.05 & -0.04 & & \\
\hline \multirow[t]{2}{*}{$\begin{array}{l}\text { EQ-5D } \\
\text { Pain/Discomfort }\end{array}$} & Scores & $\begin{array}{l}2.13 \pm \\
0.34(47) \\
\end{array}$ & $\begin{array}{l}1.62 \pm \\
0.49(39) \\
\end{array}$ & $\begin{array}{l}1.66 \pm \\
0.55(32) \\
\end{array}$ & $\begin{array}{l}1.59 \pm \\
0.50(29) \\
\end{array}$ & $\begin{array}{l}1.30 \pm \\
0.57(20) \\
\end{array}$ & \multirow[t]{2}{*}{$p<0.0001$} & \multirow[t]{2}{*}{$\begin{array}{l}\text { T0 vs T3, T6, } \\
\text { T12; T24 }\end{array}$} \\
\hline & $\begin{array}{l}\text { Difference } \\
\text { with } \\
\text { baseline } \\
\text { score }\end{array}$ & & -0.51 & -0.47 & -0.54 & -0.83 & & \\
\hline \multirow[t]{2}{*}{$\begin{array}{l}\text { EQ-5D Usual } \\
\text { Activities }\end{array}$} & Scores & $\begin{array}{l}1.72 \pm \\
0.50(47) \\
\end{array}$ & $\begin{array}{l}1.54 \pm \\
0.51(39) \\
\end{array}$ & $\begin{array}{l}1.31 \pm \\
0.47(32) \\
\end{array}$ & $\begin{array}{l}1.28 \pm \\
0.45(29) \\
\end{array}$ & $\begin{array}{l}1.30 \pm \\
0.57(20) \\
\end{array}$ & \multirow[t]{2}{*}{$p=0.0001$} & \multirow[t]{2}{*}{$\begin{array}{l}\text { T0 vs T6, T12; } \\
\text { T24 }\end{array}$} \\
\hline & $\begin{array}{l}\text { Difference } \\
\text { with } \\
\text { baseline } \\
\text { score }\end{array}$ & - & -0.18 & -0.41 & -0.45 & -0.42 & & \\
\hline \multirow[t]{2}{*}{ EQ-5D Self-Care } & Scores & $\begin{array}{l}1.21 \pm \\
0.41(47) \\
\end{array}$ & $\begin{array}{l}1.08 \pm \\
0.27(39) \\
\end{array}$ & $\begin{array}{l}1.03 \pm \\
0.18(32) \\
\end{array}$ & $\begin{array}{l}1.03 \pm \\
0.19(29) \\
\end{array}$ & $\begin{array}{l}1.05 \pm \\
0.22(20) \\
\end{array}$ & \multirow[t]{2}{*}{$\begin{array}{l}\text { Not } \\
\text { significant }\end{array}$} & \multirow[t]{2}{*}{-} \\
\hline & $\begin{array}{l}\text { Difference } \\
\text { with } \\
\text { baseline } \\
\text { score }\end{array}$ & - & -0.14 & -0.18 & -0.18 & -0.16 & & \\
\hline \multirow[t]{2}{*}{$\begin{array}{l}\text { EQ-5D } \\
\text { Thermometer Sc. }\end{array}$} & Scores & $\begin{array}{l}66.91 \pm \\
27.69(47)\end{array}$ & $\begin{array}{l}83.59 \pm \\
15.49(39)\end{array}$ & $\begin{array}{l}80.25 \pm \\
20.50(32)\end{array}$ & $\begin{array}{l}83.03 \pm \\
14.27(29)\end{array}$ & $\begin{array}{l}81.50 \pm \\
14.78(20)\end{array}$ & \multirow[t]{2}{*}{$p=0.001$} & \multirow[t]{2}{*}{$\begin{array}{l}\text { T0 vs T3, T6, } \\
\text { T12; T24 }\end{array}$} \\
\hline & $\begin{array}{l}\text { Difference } \\
\text { with } \\
\text { baseline } \\
\text { score }\end{array}$ & - & 16.67 & 13.34 & 16.12 & 14.59 & & \\
\hline
\end{tabular}

$p$-value for significance after Bonferroni correction is $<0.006$. 
shock waves, the number of shocks, and the number of sessions must also be considered when evaluating the efficacy of ESWT. Nevertheless, we point out that the protocol used to administer extracorporeal shock wave treatment in the ASSERT is based on the evidence produced by Level I studies in this field ${ }^{13}$. Nevertheless, we acknowledge that more high-quality and well-conducted studies are necessary. A database such as ASSERT could be a valid method for the systematic collection of large amount of data and for the standardization of procedures to obtain strong evidences in this field.

Concerning its limitations, this study is not a randomised controlled trial. However, Level I studies have been conducted in the present field, and have shown that ESWT, when administered according to well established protocols ${ }^{13}$, is safe and effective in the management of the condition at hand. The NICE suggested that the effectiveness of ESWT in "real life" would have needed to be evaluated in a pragmatic fashion, using standardised protocols and well validated clinically relevant outcome measures. The ASSERT protocol is NICE compliant, and satisfies the requirements set out by NICE $^{14}$.

The fact that many different clinicians were involved in the treatment, after appropriate certified training and standardisation of the protocol, and that the effects of treatment were evaluated by independent individuals, increases the generalizability of the present findings, and, in this respect, should be considered a major strength of the present study. Also, all patients had previously failed a variety of conservative management means, and this was a major criterion to be recruited in the present study.

In conclusion, when administered in a standardised fashion to an unselected population of patients suffering from tennis elbow, ESWT therapy is safe and effective in alleviating symptoms for up to 24 months.

\section{Compliance with ethical standards}

\section{Conflict of interest}

All Authors declare no conflict of interest.

\section{Funding}

The ASSERT Database has been developed and established through funds provided by Industry (Spectrum Technology UK) and ESPRC grants.

\section{Acknowledgements}

We thank Mr Jim Westwood and Mr Chris Schiel from Spectrum Technology for their support. Mr Nathan Bentley of twotwentyseven London Ltd - a creative digital agency developed the ASSERT platform following the direction of Professor Nicola Maffulli and Mrs Gayle Maffulli.

We thank all the clinicians recruiting participants onto the ASSERT database and the participants of ASSERT. Professor Nicola Maffulli developed the concept of ASSERT.

\section{Ethical approval}

All procedures performed in this study involving human participants were in accordance with the ethical standards of the institutional and/or national research committee and with the 1964 Helsinki Declaration and its later amendments or comparable ethical standards.

\section{Informed consent}

Informed consent was obtained from all individual participants included in the study.

\section{References}

1. Furia JP. Safety and efficacy of extracorporal shock wave therapy for chronic lateral epicondylitis. Am J Orthop. Chatham NJ. 2005;34(1):13-19.

2. Ko JY, Chen HS, Chen LM. Treatment of lateral epicondylitis of the elbow with shock waves. Clin Orthop. 2001;387:60-7. 71.

3. Ozturan KE, Yucel I, Cakici H, Guven M, Sungur I. Autologous blood and corticosteroid injection and extracoporeal shock wave therapy in the treatment of lateral epicondylitis. Orthopedics. 2010;33(2):84-91.

4. Radwan YA, EISobhi G, Badawy WS, Reda A, Khalid S. Resistant tennis elbow: shock-wave therapy versus percutaneous tenotomy. Int Orthop. 2008;32(5):671-677.

5. Rompe JD, Decking J, Schoellner C, Theis C. Repetitive low-energy shock wave treatment for chronic lateral epicondylitis in tennis players. Am J Sports. Med. 2004;32 (3):734-743.

6. Rompe JD, Eysel P, Hopf C, Krischek O, Vogel J, Burger $\mathrm{R}$, et al. Extracorporeal shockwave therapy in orthopedics. Positive results in tennis elbow and tendinosis calcarea of the shoulder. Fortschritte der Medizin. 1997;26(18):29-33.

7. Spacca G, Necozione S, Cacchio A. Radial shock wave therapy for lateral epicondylitis: a prospective randomised controlled single-blind study. Europa Medicophysica. 2005;41(1):17-25.

8. Buchbinder R, Green SE, Youd JM, Assendelft WJ Barnsley L, Smidt N. Systematic review of the efficacy and safety of shock wave therapy for lateral elbow pain. $J$ Rheumatol. 2006;33:1351-1363.

9. Helbig K, Herbert C, Schostok T, Brown M, Thiele R. Correlations between the duration of pain and the success of shock wave therapy. Clin Orthop. 2001;387:68-71.

10. Rompe JD, Meurer A, Nafe B, Hofmann A, Gerdesmeyer L. Repetitive low-energy shockwave application without local anaesthesia is more efficient than repetitive low-energy shock wave application with local anaesthesia in the treatment of chronic plantar fasciitis. J Orthop Res. 2005; 23:931-941.

11. Labek G, Auerdsperg V, Ziernhold M, Poulios N, Bohler $\mathrm{N}$. Influence of local anaesthesia and energy level on the clinical outcome of extracorporeal shock wave-treatment of chronic plantar fasciitis. Z Orthop Ihre Grebzgeb. 2005;143:240-246. 
12. Thiele $\mathrm{S}$, Thiele R, Gerdesmeyer L. Lateral epicondylitis: this is still a main indication for extracorporeal shockwave therapy. Int J Surg. 2015;24:165-170.

13. Rompe JD, Maffulli N. Repetitive shock wave therapy for lateral elbow tendinopathy (tennis elbow): a systematic and qualitative analysis. Br Med Bull. 2007;83:355-378.

14. National Institute for Health and Care Excellence (NICE). 2009. Treating tennis elbow using shockwave therapy. https://www.nice.org.uk/guidance/ipg313/documents/extracorporeal-shockwave-therapy-for-refractory-tennis-elbow-interventional-procedures-consultation.

15. Maffulli G, Hemmings S, Maffulli N. Assessment of the Effectiveness of Extracorporeal Shock Wave Therapy (ESWT) For Soft Tissue Injuries (ASSERT): An Online Database Protocol. Transl Med @ UniSa. 2014;10:46-51.

16. Padulo J, Oliva F, Frizziero A, Maffulli N. Muscles, Ligaments and Tendons Journal - Basic principles and recommendations in clinical and field science research: 2016 update. MLTJ. 2016;6(1):1-5.

17. Gerdesmeyer L, Wagenpfeil S, Haake M, Maier M, Loew M, Wörtler K, et al. Extracorporeal Shock Wave Therapy for the Treatment of Chronic Calcifying Tendonitis of the Rotator Cuff: a randomized controlled trial. JAMA. 2003; 290:2573-2580.

18. EuroQol-Group. EuroQol: a new facility for the measurement of health related quality of life. Health Policy. 1990;16:199-208.

19. Scott J, Huskisson EC. Graphic representation of pain. Pain. 1976;2:175-184.

20. Rompe JD, Overend TJ, MacDermid JC. Validation of the patient-rated tennis elbow evaluation questionnaire. $J$ Hand Ther. 2007;20:3-11.

21. Rompe JD, Hopf C, Küllmer K, Heine J, Bürger R. Anal- gesic effect of extracorporeal shock-wave therapy on chronic tennis elbow, J Bone Jt Surg Br. 1996;78:233-237.

22. Pettrone FA, McCall BR. Extracorporeal shock wave therapy without local anaesthesia for chronic lateral epicondylitis. J Bone Jt Surg Am. 2005;87:6:1297-1304.

23. Spacca G, Necozione S, Cacchio A. Radial shock wave therapy for lateral epicondylitis: a prospective randomised controlled single-blind study, Eura Medicophys. 2005;41 (1):17-25.

24. Radwan Y, Elsobhi G, Badawy W, Reda A, Khalid S. Resistant tennis elbow: shock-wave therapy versus percutaneous tenotomy. Int Orthop. 2008;32(5):671-677.

25. Gündüz R, Malas FU, Borman P, Kocaoglu S, Ozçakar L. Physical therapy, corticosteroid injection, and extracorporeal shock wave treatment in lateral epicondylitis: clinical and ultrasonographical comparison. Clin Rheumatol. 2012;31(5):807-812.

26. Crowther MAA, Bannister GC, Huma H, Rooker GD. A prospective, randomised study to compare extracorporeal shock-wave therapy and injection of steroid for the treatment of tennis elbow, J Bone Jt Surg Br. 2002;84 (5):678679.

27. Speed CA, Nichols D, Richards C, Humphreys H, Wies JT, Burnet S, Hazleman BL. Extracorporeal shock wave therapy for lateral epicondylitisea double blind randomised controlled trial. J Orthop Res. 2002;20(5):895898.

28. Melikyan EY, Shahin E, Miles J, Bainbridge LC. Extracorporeal shock-wave treatment for tennis elbow. a randomised double-blind study. J Bone Jt Surg Br. 2003; 85(6):852-855. 